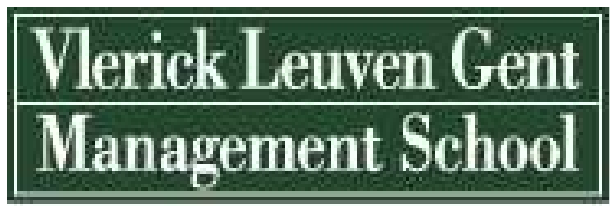

the Automunen Management School of

Chest Laiversity und Katholinks Univeraiteit Itaven

Vlerick Leuven Gent Working Paper Series 2007/10

THE OPTIMAL RATING PHILOSOPHY FOR THE RATING OF SMES

FRIEDA RIKKERS

ANDRÉ E. THIBEAULT

Andre.Thibeault@vlerick.be 


\title{
THE OPTIMAL RATING PHILOSOPHY FOR THE RATING OF SMES
}

\author{
FRIEDA RIKKERS \\ Nyenrode University \\ ANDRÉ E. THIBEAULT \\ Vlerick Leuven Gent Management School
}

\footnotetext{
Contact:

André E. Thibeault

Vlerick Leuven Gent Management School

Tel: +32092109244

Fax: +32092109700

Email: André.Thibeault@vlerick.be
} 


\begin{abstract}
The objective of this research is to determine the optimal rating philosophy for the rating of SMEs, and to describe the consequences of the chosen philosophy on several related aspects. As to our knowledge, this is the first paper that studies the considerations of financial institutions on what rating philosophy to adopt for specific portfolios.
\end{abstract}

The importance for banks to have a solid risk framework to predict credit risk of their counterparties is well reflected by the quality and the quantity of research on this subject. Moreover, a good risk framework is vital to become compliant with the new Basel II framework.

Problem is that financial institutions nearly always neglect the first step in the rating model development process: the determination of the rating philosophy. It is very important for financial institutions to decide whether they want their internal rating systems to grade borrowers according to their current condition (point-in-time), or their expected condition over a cycle and in stress (through-the-cycle), because the rating philosophy influences many aspects such as: credit approval, pricing, credit and portfolio monitoring, the regulatory and internal capital requirements and the competitive position of a bank. This makes the question which rating philosophy to use very important.

Moreover, many different modelling techniques exist to determine credit risk, but few attempts have been devoted to credit risk assessment of small commercial loans, although SME exposures are relatively important for European banks. SMEs have specific characteristics that influence the rating philosophy and therefore the development and use of credit risk models. These SME characteristics are taken into account in the analysis to determine the optimal rating philosophy.

Keywords: rating philosophy, small business, Basel II, credit rating, banks

JEL classification codes: $\quad$ D82, E32, G20, G28, G33 


\section{INTRODUCTION}

The aim of this paper is to give insight in the considerations of financial institutions ${ }^{1}$ on what rating philosophy to adopt for specific portfolios.

One of the highest risks a bank faces is the risk that one of the bank's counterparties goes into default, not repaying interest and/or principal. A solid framework for measuring credit risk is therefore of the utmost importance for a bank to manage and control its credit risks properly. The importance for banks to have a solid risk framework to predict credit risk of their counterparties is well reflected by the quality and the quantity of research on this subject.

Moreover, a good risk framework is vital to become compliant with the new Basel II framework. The Basel II IRB approach requires banks to have an internal measure of credit risk, to determine the probability of default (PD) of their clients. Banks capital requirements are based on their own assessment of the PD of individual borrowers. However, most banks have difficulties in establishing credible and reliable estimates of their risk factors.

A problem is that financial institutions nearly always neglect the first step in the rating model development process: the determination of the rating philosophy. It is very important for financial institutions to understand whether they want their internal rating systems to be point-in-time oriented (PIT), through-the-cycle (TTC) oriented, or follow a mixed approach, in other words the kind of information they want the rating to summarize. Without knowing this, it is difficult either to interpret the results of backtesting, or to assess what will happen to the capital requirements during an economic cycle. However only few financial institutions seem to clearly have made a choice (Bank of Japan, 2005). Some financial institutions have bought external rating models, for example Moody's RiskCalc ${ }^{\mathrm{TM}}$. Also when using external vendor models, banks should be aware of their rating philosophy, whether their rating models match with the (pre)defined philosophy, and what the consequences are of using a model with a specific philosophical basis.

The rating philosophy is the view of a financial institution how rating assignments are affected by the bank's choice of the range of economic, business and industry conditions that are considered in the rating process (FED, 2006). 
In PIT ratings, risks are evaluated based on the current condition of a firm regardless of the phase of the business cycle at the time of evaluation (Bank of Japan, 2005). TTC ratings look through temporary changes in credit risk, regardless of whether they are aggregate, industry or firm specific in nature.

They indicate the ability of a firm to survive through the business and economic cycle, or the life of the loan.

- The rating philosophy is of key importance as it affects:

- Rating volatility;

- Internal rating model power and quality;

- Pricing;

- Early warning of defaults;

- Calculations of expected and unexpected losses;

- Regulatory and internal capital requirements;

- Validation, backtesting and stress testing;

- The competitive position of a bank.

Moreover, many different modelling techniques exist to determine credit risk, but few attempts have been devoted to credit risk assessment of small commercial loans, although SME exposures are a relatively high share of bank loan portfolios for European banks. Because rating agencies do not provide SME ratings, financial institutions must develop (or buy) rating models to determine the credit risk of these counterparties. SMEs have specific characteristics that influence the rating philosophy and therefore the development and use of credit risk models. Small firms are informationally opaque (Peterson, 1999), volatile, and the relatively small size of each loan implies that since lenders face fixed costs in lending, lending to small firms is by definition more expensive. The lack of data has made SME credit risk an underresearched area in finance. There are only a few studies on PD estimation specifically for SMEs, for example an article by Edminster (1972), a paper by Altman and Sabato (2005), and Moody's RiskCalc ${ }^{\mathrm{TM}}$ (Falkenstein, Boral and Carty, 2000).

The objective of this research is to determine the optimal rating philosophy for the rating of SMEs by financial institutions, and to describe the consequences of the chosen philosophy on several related aspects. 
As to our knowledge, this is the first paper that studies the considerations of financial institutions on what rating philosophy to adopt for specific portfolios. Most papers on rating philosophy focus on the rating philosophy of rating agencies, while this paper focuses on the rating philosophy of financial institutions. The closest work is of Taylor (2003), the Financial Services Authority (2005) and Catarineu-Rabell, Jackson and Tsomocos (2003).

The other goals of this research are: to give insight in the rating philosophy concept, and to provide an extensive overview of the characteristics of SMEs that influence the rating philosophy. These specific SME characteristics are taken into account in the analysis to determine the optimal rating philosophy.

The remainder of this paper is structured as follows. In the next sections, credit risk (2), rating philosophy (3) and the characteristics of SMEs that influence the rating philosophy (4) are described. Then, the analysis of the optimal rating philosophy for SMEs (5) and the consequences are presented (6). The paper ends with a summary and some concluding remarks (7).

\section{CREDIT RISK}

\subsection{Credit risk}

Credit risk is the risk that those who borrow money from a bank do not pay back interest and/or principal in a timely manner or at all. Credit risk consists of three components:

- Probability of default (PD): the probability of a default, during a given period of time (assessment period). Default means not receiving interest and principal as specified in the debt agreement.

- Credit exposure (EAD): the outstanding obligation when the default occurs.

- Recovery rate (RR): the fraction of the exposure that may be recovered in the event of a default. The loss given default (LGD) is one minus the recovery rate. 
Each of the above items is critical for determining credit risk. The PD is most important, but also most difficult to determine. Prior to default, there is no way to discriminate unambiguously between firms that will default and those that won't during the next year(s). At best a probabilistic assessment of the probability of default can be made.

Under the revised Basel framework, the IRB approach requires banks to estimate the PD of all their clients. The PD is used for the calculation of the regulatory capital requirements. Basel II uses the following definition for the probability of default. "The PD is the probability that a borrower meets the default definition within one year, expressed as a percentage. A default is considered to have occurred with regard to a particular obligor when either or both of the following events have taken place:

- The obligor is 90 days past due on any material credit obligation to the banking group;

- The obligor is unlikely to pay its credit obligations to the banking group" (Basel Committee on Banking Supervision, 2006).

PD's can be stressed or unstressed. Stressed PD's give an indication of the likelihood of default, assuming adverse stress-scenario economic conditions. Unstressed PD's are unbiased estimates of the probability of default. 


\subsection{Credit Risk models}

To measure credit risk (PD) on individual banks loans, banks use credit risk models, also called rating or credit scoring models. Rating is a process of classifying exposures into different grades that indicate the ability and willingness of counterparties to pay. Each grade matches with a PD range. For the development of internal rating models to measure the probability of default, several methodologies or techniques exist:

- Statistical models (neural networks and multivariate credit scoring models such as discriminant analysis (Altman, 1968) and logistic regression);

- Hybrid models (models that combine expert knowledge and statistics);

- Expert judgement.

Different kinds of obligors require different rating models. SME business is riskier than large corporate lending (Altman and Sabato, 2005). SMEs support a risk premium on their indebtness; mainly because of the lack on information on the risk they represent (Rivaud-Danset, Dubocage and Salais, 1998). As a consequence, banks should develop credit risk models specifically addressed to SMEs, in order to minimize their expected and unexpected losses. For privately held firms with no market data available, accounting-based statistical credit scoring methods are the most common approach.

\subsection{Credit risk modelling process}

The credit risk modelling process contains of three main activities, as displayed in figure 1. Basel II is a precondition in this process. The rating philosophy is the starting point. The rating philosophy influences the rating systems design, and therefore the ratings systems, and the rating system use. Because of this, it is very important to first decide on the rating philosophy, before developing (or buying) rating systems.

Insert Figure 1 About Here 


\section{RATING PHILOSOPHY}

\subsection{Rating Philosophy}

A rating philosophy is how the bank's obligor rating assignments are affected by the bank's choice of the range of economic, business, and industry conditions that are considered in the rating process (FED, 2006). A rating philosophy is the expected behaviour with respect to the economic and industry cycles. The rating philosophy indicates the nature of the rating, i.e. what kind of information the rating intends to summarize (Löffler, 2004). The time horizon of assessing the creditworthiness of borrowers in assigning ratings is part of the rating philosophy.

Rating system approaches may be characterized as being on a spectrum between:

- Point-in-time (PIT) approaches;

- Through-the-cycle (TTC) approaches.

The choice for a specific rating philosophy is a trade-off between:

- Quality; do the ratings give a right indication of the probability of default?

- Timeliness; are the ratings based on the current situation of the company?

- Volatility; how often do the ratings migrate?

\subsection{Basel II requirements}

"A bank needs to specify its rating philosophy, that is, how the bank's wholesale obligor rating assignments are affected by the bank's choice of the range of economic, business, and industry conditions that are considered in the obligor rating process. The philosophical basis of a bank's ratings system is important because, when combined with the credit quality of individual obligors, it will determine the frequency of obligor rating changes in a changing economic environment. 
Rating systems that rate obligors based on their ability to perform over a wide range of economic, business, and industry conditions, sometimes described as "through-the-cycle" systems, would tend to have ratings that migrate more slowly as conditions change. Banks that rate obligors based on a more narrow range of likely expected conditions (primarily on recent conditions), sometimes called "point-intime" systems, would tend to have ratings that migrate more frequently. Many banks will rate obligors using an approach that considers a combination of the current conditions and a wider range of other likely conditions. In any case, the bank would need to specify the rating philosophy used and establish a policy for the migration of obligors from one rating grade to another in response to economic cycles. A bank should understand the effects of ratings migration on its risk-based capital requirements and ensure that sufficient capital is maintained during all phases of the economic cycle" (FED, 2006).

\subsection{Point-in-time}

In the point-in-time (PIT) rating method, risks are evaluated based on the current condition of a firm regardless of the phase of the business cycle at the time of evaluation. A PIT PD is unstressed. PIT rating systems take all cyclical and noncyclical, systematic and obligor specific information into account. The essential feature of a PIT rating system is that it aims explicitly to forecast default probability over a set period, typically one year (Financial Services Authority, 2005).

Under a $100 \%$ PIT system, the rating changes as soon as the borrower's condition changes. Obligors are constantly assigned to new ratings whose PDs reflect the forward looking default likelihood, based on the best available information about their current credit quality. PIT systems are defined by current PD's that reflect the current creditworthiness of the counterparty.

In case of perfect models, defaults actually experienced should match the predicted defaults every year. Under a PIT system, the risk rating to the PD mapping is kept constant. A PIT system can be defined by volatile ratings, due to frequent rating migrations, but constant PDs per rating grade. Ex-post default rates per grade are stable regardless of the business cycle (Bank of Japan, 2005). 
PIT rating systems are cyclical and forward-looking. In general, PIT ratings tend to rise during economic upturns, as most obligors' creditworthiness improves and tend to fall during economic downturns.

\subsection{Through-the-cycle}

In literature, there is no consensus on what is precisely meant by TTC.

In this research TTC is defined as a measure of the ability of an obligor to remain solvent at the trough of a business or economic cycle or during severe stress events (Treacy and Carey, 2000). This means that risk default rates are estimated for a borrower's conditions at the bottom of the economic or industry cycle and under stress. In case the life of the loan is shorter than the economic or business cycle, the term of the loan is used.

The ratings are based on a variety of longer-run considerations, financial and non-financial, quantitative and qualitative. The TTC rating methodology requires a separation of permanent and cyclical components in default risk. The essential feature of a TTC system is that it seeks to produce ratings that do not vary with cyclical movements (a cyclical), although the ratings of individual companies will fluctuate due to changes in their own position and prospects. TTC ratings only respond to permanent shocks to the firm, transitory shocks are ignored (Löffler, 2004).

In TTC rating, the rating grades of firms remain the same through the business cycle, but ex-post default rates within the same grade fluctuate reflecting the business cycle (Bank of Japan, 2005). A TTC system can be defined by stable ratings but realised PDs per rating grade vary over the cycle.

The rating agencies, such as Moody's and S\&P, follow a TTC rating approach; agency ratings are assigned based on an estimate of the borrowers default probability in a stress scenario. 


\subsection{Differences between PIT and TTC ratings}

Pure TTC or PIT systems do not exist in practice in the commercial world (Financial Services Authority, 2005). It is not possible to include all information in a rating, as is required in a PIT rating, simply because not all information is available to a bank, due to information asymmetry and information that is not sufficiently forward looking. Besides, there might be resistance from account managers to downgrade certain obligors too quickly. It is also not possible to exactly know what the worst conditions are in a cycle and to simulate these, and to split all information in cycle or company specific, as should be done under the TTC approach. However, ratings systems can be very close to true TTC or PIT systems.

\section{Volatility}

The extend to which banks need to downgrade borrowers during a recession, depends for a large part on the way the PD is determined. TTC rating systems tend to have ratings that migrate slowly as conditions change. The PDs arising from a TTC system will be stable and cyclically neutral. TTC systems have a clear advantage in preventing the regulatory and internal capital requirements becoming procyclical.

PIT rating systems that rate obligors on a more narrow range of expected conditions (both permanent and transitory shocks), tend to have ratings that migrate more frequently. Under a PIT philosophy the PDs assigned to individual obligors are volatile and can be expected to move counter-cyclically, see figure 2.

\section{Insert Figure 2 About Here}

\section{Quality and timeliness}

There are two types of rating errors. A type I error means classifying a firm as not likely to default, when it actually does default, i.e. a false positive. A type II error means classifying a firm as likely to default when it does not default. Both errors create different types of economic costs for a firm.

Insert Table 1 About Here 
The more PIT the PDs are, the more forward looking and thus predictive they are. In case of a PIT rating system, there is a risk that a company wrongly is seen as risky (type II error), because all information is included in the rating.

Under a TTC or hybrid (PIT/TTC) approach, a borrower's rating grade won't be fully sensitive to factors affecting the likelihood of the company defaulting in the next 12 months, such as whether the industry may be at or approaching a cyclical peak. Some risk sensitivity is rejected because up-to-date information is not used. Under a TTC rating system, it is therefore probable that some of the more risky clients remain unnoticed (type 1 error, false positive), because the actual creditworthiness is ignored in the rating.

According to Miu and Ozdemir (2005), the correlation of credit risks under a PIT system should be much lower than under a TTC system. Therefore, default probability forecasts should be more precise (Rösch, 2004).

It is probable that because the TTC rating does not necessarily reflect true credit risk, the attitude towards the ratings by both the business and the credit risk department are not positive, and that therefore the rating is not used in practice.

\section{Defaults per grade}

A main difference between PIT en TTC ratings is whether changes in the economic environment surrounding, borrowers are absorbed by rating migrations as in PIT, or are incorporated into changes in the actual default rate of each grade as in TTC (Bhatia, 2006).

Under the PIT system, if the models were perfect, defaults actually experienced in each grade should match the prediction in each and every year. Under a TTC system, the observed annual default rate in each grade may be expected to vary from the long run average in accordance with movements in the cycle.

\section{Effort}

Trying to "look through the cycle" as a company's performance fluctuates is a challenge. It involves separating cyclical influences from those that are secular (i.e., longer-term trend) or seasonal, separating systematic (i.e., industry- or economy-wide) factors from those that are idiosyncratic (i.e., company specific) (Taylor, 2003). Therefore, a TTC rating requires more data and analysis than PIT grading. 
Under the TTC approach, a downsize or stress scenario is estimated for the borrower and the rating is assigned based on the borrowers projected condition in the event the scenario occurs. The stress scenario used in the TTC rating approach is a deviation from the normal condition which is of a cyclical nature and which occurs with a certain probability over a predefined horizon. Permanent and cyclical components of default risk are typically not directly observable, but have to be estimated (Löffler, 2004). Besides, an institution putting in place a TTC approach has to handle differences in industries carefully. Different industries have different cycles, and when using the wrong cycle; the long-run PD value may not be relevant. All this means that the determination of a TTC rating requires complex (statistical) analyses.

Complex analyses means that TTC grading entails greater expense, and for many middle market credits the extra expense might render such lending unprofitable for banks (Treaty and Carey, 2000).

\section{Validation}

Basel II requires that financial institutions validate their rating systems. Backtesting is part of the validation process and is the comparison of actual outcomes against predictions. Under a pure PIT system, the realised PDs will not deviate from the expected PDs, because all credit risk related information is incorporated in de rating. TTC ratings give an indication of the creditworthiness over a total economic cycle. The predicted TTC PDs will match the average realised PD during a total cycle. The more deviation between the predicted and the realised PD is, the more difficult the validation of the rating models. PIT PDs should be validated against the 12-month default rates, whereas TTC PDs against some kind of cycle average default rates (Miu and Ozdemir, 2005). Validation of a TTC system is therefore more complicated than of a PIT system.

Another dimension of validation is testing whether the rating philosophy is realised in the rating systems. This analysis can be done by a rating migration analysis. The more PIT the ratings are, the higher the migration rate should be.

Since rating philosophies applies to both PDs and default (or asset) correlations, the validation needs to be consistent with both PDs and their correlations. Any inconsistencies (such as PDs are intended to be PIT, whereas correlations are TTC) can distort the validation results (Miu and Ozdemir, 2005). 


\subsection{Hybrid}

Few financial institutions seem to clearly make a choice between PIT and TTC ratings. They seem to evaluate the creditworthiness of borrowers over some period, for example, three to five years, indicating that their choice is somewhere between the above two types of ratings (Bank of Japan, 2005).

The hybrid rating philosophy is the area between PIT and TTC. In a hybrid rating system, both the borrower's current condition, outlook and cycle effects are included in the rating. Only substantial changes in the creditworthiness influence the rating. Short-term fluctuations, as included in the PIT rating are ignored. Ratings are not continuously reviewed, but on fixed moments in time. In a hybrid rating model, fluctuations in the economic or business cycles result in a combination of rating grade migration and changes in the level of default experienced in each grade (Financial Services Authority, 2005). Hybrid rating models can be close to PIT, TTC or somewhere in the middle.

\subsection{Rating horizon}

The rating horizon indicates on what time period the rating is based, see figure 3. Basel II uses a rating horizon of one year; "the PD is the probability that a borrower meets the default definition within one year" (Basel Committee on Banking Supervision, 2006).

PIT ratings are based on the expected developments of the creditworthiness of the client over a maximum of a year. A TTC rating looks forward through the cycle and takes the average PD over a complete cycle, to estimate a one-year PD.

Insert Figure 3 About Here 


\subsection{Relevance of a rating philosophy}

The philosophical basis of a bank's rating system is of key importance as it affects:

- Rating volatility;

- Internal rating model power and quality;

- Pricing;

- Early warning of defaults;

- Calculations of expected and unexpected losses;

- Regulatory and internal capital requirements;

- Validation, backtesting and stress testing;

- The competitive position of a bank.

Though we cannot judge a priori which rating method is better than the other for certain banks, it is still very important for financial institutions to understand whether their own internal rating systems are more PIT-oriented, TTC-oriented, or follow a hybrid approach, in other words, what kind of information their ratings summarize.

The optimal rating philosophy is determined by the rating objectives of the bank. The choice for a PIT or TTC rating philosophy is a trade-off between quality, timeliness and volatility. Whatever rating philosophy banks choose, to have a clear rating philosophy and to understand the consequences is very important because, when combined with the credit quality of individual obligors, it will determine the frequency of obligor rating changes in a changing economic environment (FED, 2006).

Without knowing the rating philosophy, it is difficult either to interpret the results of backtesting of actual outcomes against predictions, or to assess what will happen to the capital requirements as the cycle fluctuates (Financial Services Authority, 2005). 


\section{SMES}

\subsection{Definition of SMEs}

Financial institutions and banks have built many statistical models to measure the risk of their loan portfolio. However, no single type of model is suitable across all portfolios. Few attempts have been devoted to small commercial loans credit risk, although small and medium-sized enterprise (SME) exposures are a relatively high share of bank loan portfolios, especially in Europe. For OECD members, the percentage of SMEs out of the total number of firms is greater than 97\% (Altman and Sabato, 2005).

The definition of the business size: micro, small, medium, or large, results from the application of different criteria, such as the number of employees, the sales volume or the total assets.

According to the guidelines of the European Commission (2001), the following subdivision can be made:

Insert Table 2 About Here

\subsection{Characteristics of SMEs}

SME exposures have specific peculiarities. Several factors distinguish credit risk in small (SME) from large (corporate) commercial loan portfolios. These characteristics influence the relationship of the SME and the bank, the rating philosophy and therefore the credit risk modelling process.

\subsubsection{Information}

The most important characteristic defining small business finance is informational opacity. SME loans are illiquid and do not trade on secondary markets (Allen, Delong and Saunders, 2003). Small firms do not enter into contracts that are publicly visible or widely reported in the press. Contracts with suppliers and customers are generally kept private. In addition, small businesses do not issue traded securities that are continually priced in public markets. 
SMEs are often managed by a very few directors who frequently own the total capital of the firm and aim to minimize the intrusion in their business rather than reaching an optimal debt target (Aybar-Arias, Casino-Martinez, López-Gracia, 2003).

Accounting data appears only at discrete intervals, for SMEs in most cases only on a yearly basis. SMEs have in general lower quality accounting data than larger corporates. Many of the smallest firms do not have audited financial statements. As a result, small firms often cannot credibly convey their quality (Berger and Udell, 1998). The data about SMEs are of unproven quality and therefore less reliable, and it can be a challenge to extract the minimum required information in order to improve the allocation of credit (Crouhy, Galai and Mark, 2001).

On the contrary, the large corporate loan portfolio uses rich information concerning the financial situation of clients. This information comes from rating agencies and financial markets. In general, the information is available in time series, which allows trend analysis.

Most PD models use market information, as bond data, equity price data or credit default swap data. This kind of information is not available for SMEs. This data limitation restricts the modelling choices.

\subsubsection{Economy}

SMEs are sensitive to the state the economy (Rijken, 2005). They may be expected to be more likely to fail, because they (1) are less likely to benefit from scale effects, (2) have less power in negotiations with financial and social partners, (3) are less likely to benefit from their experience or 'learning effects', compared to large firms, and (4) often operate on small markets.

Due to the lack of product and market diversification, SMEs face high uncertainty about their future cash flow levels and timing. This leads to inconsistent and volatile financial statement data through time (Rijken, 2005). Financial data of one year can be totally inconsistent with the data of the next year.

SMEs meet uncertainty and need to react quickly on events. The need to have financing available in order to seize unexpected market opportunities or to react to external shocks is particularly important for the vitality of SMEs (Rivaud-Danset, Dubocage and Salais, 1998). 


\subsubsection{Costs}

The relatively small size of each loan of a small commercial loan portfolio implies that the absolute size of the credit risk on any individual loan is minimal. Losses on any single loan will not cause the bank to become insolvent (Allen, Delong and Saunders, 2003). The cost per loan of determining the credit risk is often greater than the benefit in terms of loss avoidance, because it is time consuming and expensive to extensively evaluate a loan at its individual level (Dietsch and Petey, 2002). Since lenders face fixed costs in lending, lending to small firms is by definition more expensive per dollar lent (Peterson, 1999). Therefore, methodological choices are restricted by time and cost constraints.

\subsubsection{Variation}

There is a large variation in the legal structure of small businesses (Bhatia, 2006) and in the activities of SMEs. It is therefore difficult to attain homogeneity with small businesses as the size of the exposures, types of industry and the legal structure of obligors all vary substantially. It is however not possible, also due to financial constraints to develop different credit risk models for all types of SMEs.

\subsection{Characteristics of an SME PD model}

Because of the SME characteristics described above, it's more difficult to develop an accurate PD model for SMEs, than for larger companies. The use of possible credit risk models and input variables is limited. Models developed for larger firms cannot be used for SMEs without adjustment. Default models based on public firm data and applied to (smaller) private firms will likely misrepresent actual default risk. 
Besides the general credit risk model characteristics such as: powerful, accurate, statistically robust, reliable, intuitive, and transparent, a PD model for SMEs should have the following specific characteristics (Rikkers and Thibeault, 2006):

- Time and cost efficient;

- Fast;

- Make use of the limited financial data available for SMEs;

- Be able to work with only one year of financial data;

- Broadly applicable.

\section{ANALYSIS AND RESULTS}

\subsection{Rating objectives}

The rating objectives determine the optimal rating philosophy. Rating are used for:

1. Credit approval;

2. Credit and portfolio monitoring;

3. Early warning systems;

4. Commercial activities;

5. Pricing;

6. Regulatory capital requirements;

7. Economic capital requirements;

8. Capital planning.

For the first four roles, it's advantageous to have ratings that reflect the current creditworthiness of the counterparty in the current point in the cycle and thus on how the industry and economy are currently performing.

In deciding whether to approve a new loan (1), it makes a difference whether the industry in question is nearer a peak or a trough of its cycle. This suggests a pointin-time approach, whereby borrowers are regraded immediately as their fortunes change, whatever the cause may be (Taylor, 2003). In case of credit approval of a loan with a long maturity, TTC ratings give an indication of the ability of the obligor to meet his payments till the end of the term of the loan, which is important to know in the approval process. 
For the second role, PIT grading has advantages as it indicates the current creditworthiness of counterparties. At the same time, the strategic issues involved make a longer-term viewpoint more appropriate; therefore at TTC rating might give some insights. TTC ratings can be used for budgeting purposes, human resource planning and provisions.

For early warning, only a PIT rating is appropriate. TTC ratings cannot be used as an early warning system, because the rating does not reflect the current creditworthiness of the counterparty.

Ratings are also used for commercial activities (4), for example cross-selling and marketing activities. In case a counterparty has an acceptable rating, the business can decide to actively contact this client to try to sell some other products or to expand current loans. It depends on the type of product and the life of the loan whether a PIT or TTC rating is more appropriate.

In the case of pricing (point 5), both rating philosophies have advantages. The interest rate on debt can be divided in a risk free rate and the risk premium, where the latter is based on the creditworthiness of the counterparty. When using a PIT rating system, the risk premium matches exact with the credit risk of that counterparty at that moment. However, PIT ratings lead to volatile interest rates and not all banks are willing to adjust their prices that often, and not all counterparties will accept volatile interest rates. A TTC rating causes interest rates to be stable, but they do (in most cases) not reflect the true credit risk of the counterparty.

The rating philosophy also influences the competitive position of banks. TTC ratings are on average somewhat higher than PIT ratings because they are stressed. PIT banks may therefore offer lower interest rates. There is a risk that banks using TTC ratings lose their clients during recovery, because PIT banks offer lower interest rates. The opposite happens during recessions. This is not a favourable situation.

The rating philosophy can have significant implications for the cyclicality of banks' regulatory and internal capital requirements (point 6 and 7). Research by Catarineu-Rabell, Jackson and Tsomocos (2003) shows that ratings based on TTC rating approaches lead to little, if any, increase in capital requirements for nondefaulted assets in a recession, whereas ratings based on a PIT rating model lead to a $40 \%$ to $50 \%$ increase. 
Procyclicality is derived entirely from migration between grades, and is thus based on the ratings system being used by the bank. Procyclicality refers to the tendency for regulatory capital requirements to rise with downswings in the economy and to fall with upswings (Financial Services Authority, 2005).

When using PIT ratings, the internal and regulatory capital requirements are becoming volatile and procyclical. PIT systems lead to higher capital requirements during recessions, which can lead to credit supply constraints as banks suffer capital shortages and they might perhaps even fail, which can worsen the economic situation. Substantial changes in capital requirements can increase the likelihood of a 'credit crunch'. In addition, during recessions, capital available to meet regulatory and economic capital requirements becomes more scarce as banks make more provisions and write-offs.

There is also the possibility that actions taken by individual firms to reduce their risk, e.g. by cutting back on lending will magnify the downturn by causing a credit crunch (Financial Services Authority, 2005). On the other hand, during the recovery and boom phases of the cycle, the PIT rating methodology gives the opportunity to grant extra loans, because the capital requirements are lower, and therefore stimulate the economy. Procyclical ratings can have macroeconomic consequences by encouraging overlending relative to risk in booms and reduction in lending during recessions (Catarineu-Rabell, Jackson and Tsomocos, 2003).

The capital requirements under a TTC system are not influenced by the cycle, but because the ratings are stressed (based on the worst point in the cycle), the average capital requirements under a TTC system are expected to be higher than under a PIT system. However, because TTC ratings are very stable, capital requirements are stable and therefore, capital planning becomes easier. TTC ratings can be used to determine long-term resource allocation (both capital and human).

Insert Figure 4 About Here 


\subsection{The banks portfolio}

Banks are always somewhere between a PIT and TTC rating. Whether they are close to PIT, TTC or are in the middle depends on several characteristics of the banks portfolio:

- Firm size;

- Industry;

- Country;

- Rating (PD);

- Term of the loan;

- Asset class (Basel II);

- State of the economy.

These characteristics influence the volatility and/or the rating horizon. The characteristics should be seen in combination with the rating objectives.

\section{Firm size, industry and country}

These three characteristics of the banks portfolio are very important for the determination of possible rating philosophies, because they influence the volatility of the counterparty. Different industries, firm sizes and countries have different volatilities. The more volatile a company, the shorter the rating horizon can be. (Geographical) diversification of the credit portfolio can reduce the impact of cyclicality of a portfolio.

\section{Rating (PD)}

The rating horizon is influenced by the current rating of a counterparty. The higher the probability of default, the shorter the rating horizon is. A financial institution wants a closer look on counterparty with a PD of $20 \%$, than on a counterparty with a PD of $0.5 \%$. 


\section{Term of the loan}

The choice between PIT and TTC ratings, or a mixture of the two depends also on the length of time financial institutions are exposed to the credit risk. Since the majority of a bank's loans have a long time before maturity, it is desirable to assign a grade considering creditworthiness of the counterparty over the whole period. In case of a three months loan, it has no value to determine the TTC rating over a very long horizon.

\section{Asset class}

Basel II recognizes several asset classes: corporate, sovereign, bank, retail (residential mortgage, qualifying revolving retail exposures, retail other) and equity (Basel Committee on Banking Supervision, 2006). The different asset classes require their own rating models, because each asset class has its own characteristics. Different asset classes have a different rating horizon and different volatilities.

The rating horizon for equity is shorter, than he rating horizon for residential mortgages or sovereigns, due to differences in volatility and creditworthiness.

\section{State of the economy}

During a slowdown or a recession, the rating horizon is shorter, than during recovery and boom. During recessions, the credit risk of most counterparties is negatively influenced by the cycle. In order to prevent defaults and bankruptcy, banks tend to more often revise their ratings.

\subsection{The optimal rating philosophy for SMEs}

The following table gives an indication of the average asset volatility (standard deviation) in a year, of different industries and company sizes of a Dutch SME sample $^{2}$. For the definition of micro, small and medium sized enterprises, see table 2. The table below indicates that there are differences in asset volatility between industries and company sizes.

SMEs have in general more volatile activities than large corporates. According to paragraph 4.2 , the smaller a company, the more vulnerable this company is to internal and external influences. 
The sample shows that the smaller a company, the higher the asset volatility. Manufacturing and trade companies have smaller asset volatilities than service oriented companies.

Insert Table 3 About Here

The more volatile the company, the smaller the rating horizon can be. Because of the volatile nature of SMEs, a 100\% TTC rating model cannot be used, because it is impossible to make a reliable analysis of the creditworthiness of an SME counterparty over a whole economic cycle of 10-15 years. This kind of analysis is only possible for very large corporates.

The average credit risk of SMEs is higher than that of large corporates. SMEs are less likely to benefit from scale effects, have less power in negotiations with financial and social partners, are less likely to benefit from their experience or 'learning effects', compared to large firms, and often operate on small markets. This makes SMEs more vulnerable than larger corporates.

Under a TTC rating methodology, the rating horizon is that far away that the rating doesn't give a right indication of true credit risk of SMEs.

The determination of a TTC rating requires complex (statistical) analyses, because cyclical and permanent components in default risk need to be separated and the stress scenario needs to be simulated. This makes TTC ratings much more expensive than PIT or hybrid ratings. Because the revenues on SME loans are in general small, using a TTC rating philosophy is probably unprofitable for banks with an SME portfolio.

Pure PIT rating systems however also have drawbacks. All information needs to be included in the rating; this requires a lot of effort from banks. Because the ratings become very volatile, both the interest rates and the capital requirements become very volatile and procyclical, which is not desirable. Besides, it is hard to take strategic decisions on volatile ratings.

Based on the SME characteristics, we would advise to adopt a hybrid rating philosophy with a rating horizon between one and three years, based on the size, industry, life of the loan, and current creditworthiness of the counterparty. The more volatile, or the higher the credit risk, the smaller the rating horizon should be. 
The rating objectives also should be taken into account when determining the optimal rating horizon.

The rating should be revised, based on a revision schedule (once or twice a year), or when there is a significant change in the creditworthiness of a counterparty. In that case, the rating should be adjusted between times. It is advisable to assess the degree of credit risk under the economic downturn by use of a stress test.

\section{CONSEQUENCES OF THE HYBRID RATING PHILOSOPHY}

\subsection{Rating volatility}

Under a hybrid rating philosophy, the ratings have an average volatility. The more often the ratings are revised, the more volatile they will be. However, they are not as volatile as under a PIT rating philosophy, since only substantial changes in the creditworthiness influence the rating. Short-term fluctuations, as taken into account in the PIT rating are ignored.

\section{Capital requirements}

The capital requirements are limited procyclical under a hybrid rating philosophy. Hybrid ratings do not significantly worsen the economic situation during recessions, which is the case with PIT ratings. PIT ratings can lead to a credit crunch during recessions. Since hybrid ratings are not stressed, the average capital requirements under a hybrid rating system are not significantly higher than under a PIT system, as is the case with TTC systems. Since hybrid ratings are reasonably stable, hybrid ratings can be used for (capital) planning purposes.

\section{Pricing}

The interest rates will give a true indication of credit risk, since all substantial credit risk factors are included in the rating, however they are not very volatile. Short time fluctuations are ignored. The interest rates under a hybrid rating system are not significantly higher than under PIT. The competitive position of the financial institution is therefore not negatively influenced, as is the case with a TTC rating methodology. 


\subsection{The ability to spot defaults ahead of time}

Under a hybrid rating model, all significant aspects of the current creditworthiness are included in the rating. Because transitory changes in the creditworthiness are ignored, the hybrid rating is not such a strong early warning system as a PIT rating model.

\subsection{Credit risk model development}

There are three main types of credit risk models, statistical models, hybrid models (models that combine expert knowledge and statistics) and expert judgement. The choice for a rating philosophy influences the type of credit risk model. A statistical model is in general more PIT, because the output is directly influenced by any change in the financials of a company. Expert judgement is more TTC. A hybrid rating philosophy in general matches best with a hybrid model. These models combine expert knowledge and statistics. Judgemental overrides of the rating are possible.

The rating philosophy also influences variable choice. Quantitative variables are likely to more closely approximate a PIT system, to the extent that it's driven by current market information and/or the most recent financials. Qualitative variables like market outlook and management quality are more TTC. When having a hybrid model with a horizon between one and three years, the model should contain a combination of quantitative 'PIT' and qualitative 'TTC' variables.

\subsection{Validation}

Basel II requires financial institutions to validate their rating systems. The more PIT the rating system is, the easier validation. Backtesting is part of the validation process and is the comparison of actual outcomes against predictions. Under a hybrid rating system, the predicted defaults will slightly differ from the realised defaults. The more deviation between the predicted and the realised PD, the more difficult the validation of the rating models is. Validation of a hybrid rating model is somewhat more complex than of a PIT model.

Another dimension of validation is testing whether the rating philosophy is realised in the rating systems. This analysis can be done by a rating migration analysis. The more PIT the ratings are, the higher the migration rate. Under a hybrid rating model, the migration rate is lower than under a PIT rating system. 
A way to test the realisation of the rating philosophy is to develop a PIT statistical model, as a benchmark, and compare the ratings and the rating migration of both models.

The validation process needs to be consistent with both the PDs and their correlations. Any inconsistencies (such as PDs are intended to be PIT, whereas correlations are TTC) can distort the validation results (Miu and Ozdemir, 2005).

\section{CONCLUSION}

This is the first paper that studies the considerations of financial institutions on what rating philosophy to adopt, in this case for an SME portfolio. SMEs have specific peculiarities that influence the rating philosophy and therefore the modelling of credit risk, as they are informationally opaque and volatile.

A problem is that financial institutions nearly always neglect the first step in the rating model development process: the determination of the rating philosophy. It is very important for financial institutions to understand whether they want their internal rating systems to be point-in-time oriented (PIT), through-the-cycle (TTC) oriented, or follow a mixed approach, in other words the kind of information they want the rating to summarize. In PIT ratings, risks are evaluated based on the current condition of a firm regardless of the phase of the business cycle at the time of evaluation. TTC ratings indicate the ability of a firm to survive through the business and economic cycle.

- The rating philosophy is of key importance as it affects:

- Rating volatility;

- Internal rating model power and quality;

- Pricing;

- Early warning of defaults;

- Calculations of expected and unexpected losses;

- Regulatory and internal capital requirements;

- Validation, backtesting and stress testing;

- The competitive position of a bank. 
In this research, the concept rating philosophy is worked out, and the consequences of the different rating philosophies. Also, an overview is provided of the characteristics of SMEs that influence the rating philosophy. These specific SME characteristics are taken into account in the analysis to determine the optimal rating philosophy for SMEs.

Based on the SME characteristics, we would advise to adopt a hybrid rating philosophy with a rating horizon between one and three years. The optimal rating horizon is based on the rating objectives and characteristics of the credit portfolio.

\section{FOOTNOTES}

1 Bank and financial institution are used interchangeably throughout this research.

2 The analysis is based on annual changes in book values of assets of a sample of 320 Dutch SMEs. Extreme individual asset volatilities (above 100\%) are ignored (13 of the 527 cases). 


\section{REFERENCES}

Allen, L., DeLong, G., Saunders, A. 2003. Issues in the credit risk modelling of retail markets. www.defaultrisk.com.

Altman, E.I. 1968. Financial ratios, discriminant analysis and the prediction of corporate bankruptcy. Journal of Finance 23 4: 589-609.

Altman, E.I., Sabato, G. 2005. Modeling credit risk for SMEs: Evidence from the US market. www.ssrn.com.

Aybar-Arias, C., Casino-Martinez, A., López-Gracia J. 2003. Capital structure and sensitivity in SME definition: A panel data investigation. (December) www.ssrn.com.

Bank of Japan. 2005. Advancing Credit Risk Management through Internal Rating Systems.www.boj.or.jp.

Basel Committee on Banking Supervision. 2006. International convergence of capital measurement and capital Standards. June. www.bis.org.

Berger, A.N., Udell, G.F., 1998. The economics of small business finance: The roles of private equity and debt markets in the financial growth cycle. Journal of Banking \& Finance 22 .

Bhatia, M. (2006). Credit risk management \& Basel II. Riskbooks.

Carey, M., Hrycay, M. 2001. Parameterizing credit risk models with rating data. Journal of Banking \& Finance 25, 197-270.

Catarineu-Rabell, E., Jackson, P., Tsomocos, D.P. 2003. Procyclicality and the new Basel Accord- bank's choice of loan rating system. Bank of England working paper series. www.sbs.ox.ac.uk

Crouhy, M., Galai, D., Mark, R. 2001. Prototype risk rating system. Journal of Banking \& Finance 25, 47-95.

Dietsch, M., Petey J. 2002. The credit risk in SME loans portfolios: Modelling issues, pricing, and capital requirements. Journal of Banking \& Finance 26: 303-322. 
Edminster, R.O. 1972. An empirical test of financial ratio analysis for small business failure prediction. The Journal of Financial and Quantitative Analysis, 7 2: 1477 1493.

European Commission. 2001. Amending recommendation 96/280/EC concerning the definition of small and medium-sized enterprises. ec.europa.eu.

Falkenstein, E., Boral A., Carty L.V. 2000. RiskCalc ${ }^{\mathrm{TM}}$ for private companies: Moody's default model rating methodology. www.moodyskmv.com.

Federal Reserve Bank. 2006. Risk-Based Capital Standards: Advanced Capital Adequacy Framework. www.federalreserve.gov/.

Financial Services Authority. 2005. Procyclicality of capital requirements under Basel II: aide memoire. www.fsa.gov.uk.

Löffler, G. 2004. An anatomy of rating through the cycle. Journal of Banking \& Finance 28, 11.

Miu, P., Ozdemir, B. 2005. Practical and Theoretical Challenges in Validating Basel Parameters: Key

Learnings from the Experience of a Canadian Bank. Journal of Credit Risk, Vol 1, No 4.

Peterson, M.A. 1999. The small business lending relationship. Conference on Consumer Transactions and Credit. Federal Reserve Bank of Philadelphia.

Rijken, H.A. 2005. De gevolgen van Basel II voor de individuele MKB-onderneming blijven onzeker. Accounting 5 (May).

Rikkers, F., Thibeault, A.E. (2006). A strucutral form default prediction model for SMEs, evidence from the Dutch market. Working paper.

Rivaud-Danset, D., Dubocage, E., Salais, R. 1998. Comparison between the financial structure of SMES and that of large enterprises (LES) using the BACH database. http://europa.eu.int/economy_finance. 
Rösch, D. 2004. An empirical comparison of default risk forecasts from alternative credit rating philosophies. International Journal of Forecasting 21. 37-51.

Taylor, J. 2003. Risk-grading philosophy: through the cycle versus point in time. The RMA Journal.

Treacy, W.F., Carey, M.S. 2000. Credit risk rating at large US banks. Journal of Banking \& Finance, 24. 167-201. 


\section{FIGURE 1}

\section{The credit risk modelling process}

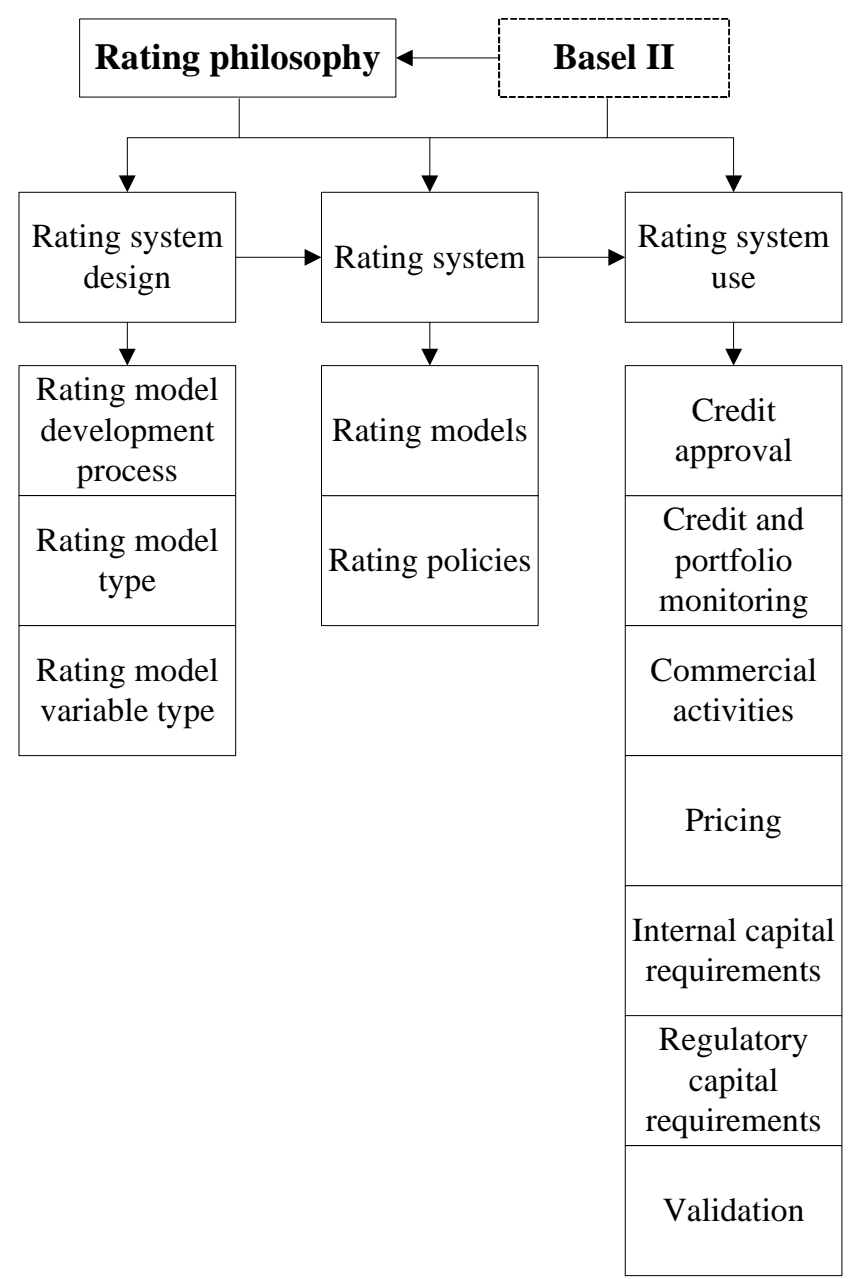




\section{FIGURE 2}

The influence of the cycle on the ratings

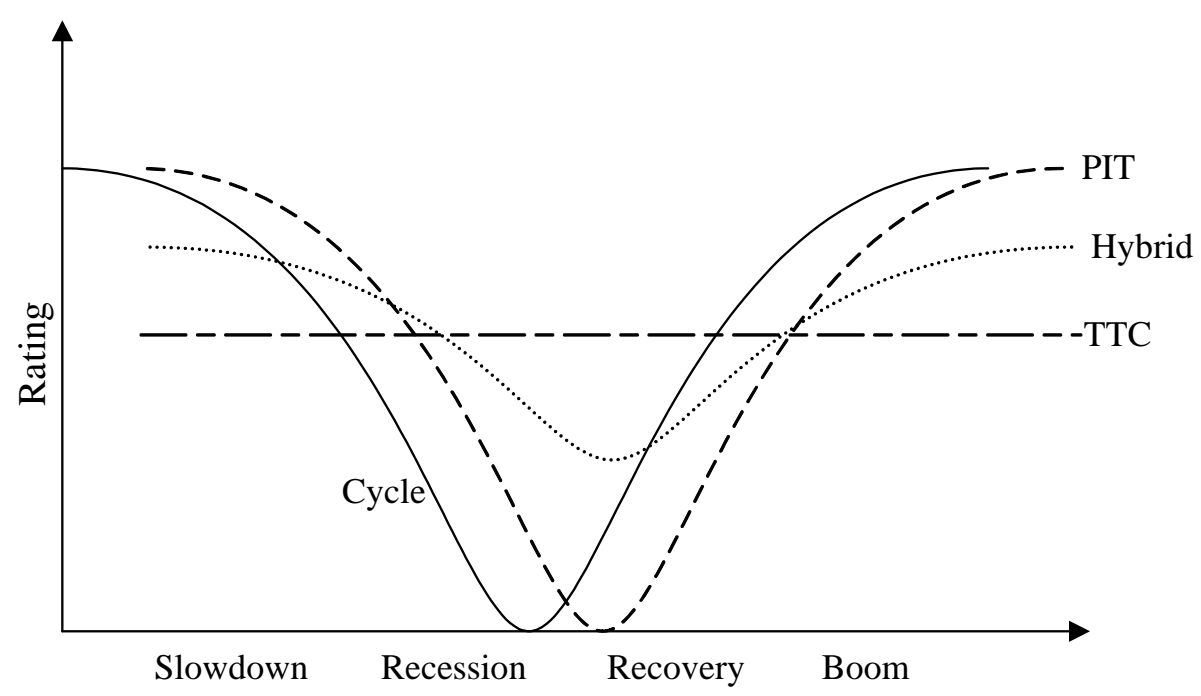


TABLE 1

Type I and II errors

\begin{tabular}{lll}
\hline & \multicolumn{2}{c}{ Estimated } \\
Observed & Non-default & Default \\
Non-default & True & Type II error \\
Default & Type I error & Hit \\
\hline
\end{tabular}


FIGURE 3

The rating horizon

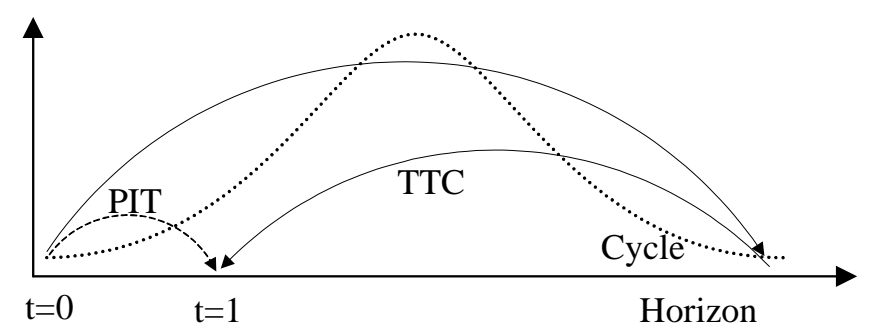




\section{TABLE 2}

The subdivision of business size

\begin{tabular}{llll}
\hline Business size & Number of employees & Annual turnover & Balance sheet total \\
Large & $>250$ & $>€ 50 \mathrm{mln}$ & $>€ 43 \mathrm{mln}$ \\
Medium & $>50-\leq 250$ & $>10-\leq € 50 \mathrm{mln}$ & $>10-\leq € 43 \mathrm{mln}$ \\
Small & $\geq 10-\leq 50$ & $\geq 2-\leq € 10 \mathrm{mln}$ & $\geq 2-\leq € 10 \mathrm{mln}$ \\
Micro & $<10$ & $<€ 2 \mathrm{mln}$ & $<€ 2 \mathrm{mln}$ \\
SME & $\leq 250$ & $\leq 50 \mathrm{mln}$ & $\leq 43 \mathrm{mln}$ \\
\hline
\end{tabular}




\section{FIGURE 4}

The influence of the cycle on the capital requirements

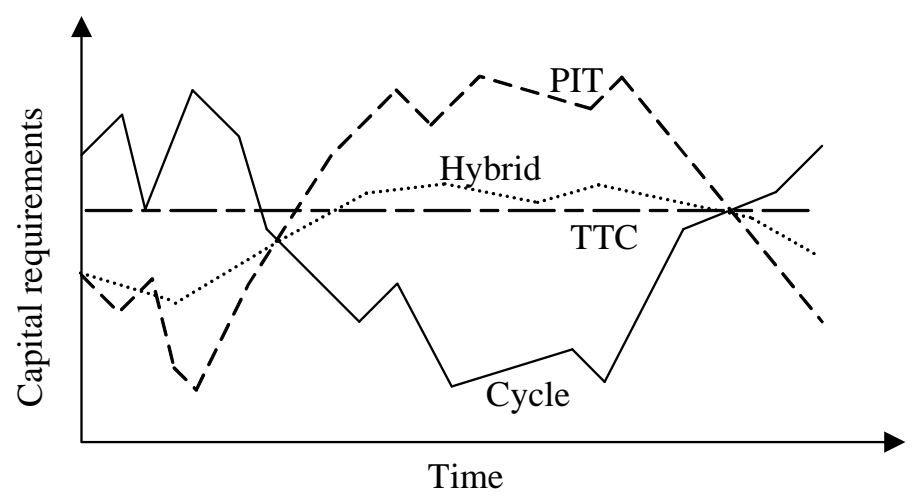




\section{TABLE 3}

The asset volatility of different company sizes and industries

\begin{tabular}{cc|cc}
\hline Industry & Asset volatility & Size & Asset volatility \\
\hline Manufacturing & $17.74 \%$ & Micro & $22.33 \%$ \\
Trade & $15.49 \%$ & Small & $16.14 \%$ \\
Service & $22.82 \%$ & Medium & $13.75 \%$ \\
\hline
\end{tabular}

